\title{
Exploratory experimental investigations on post-tensioned structural glass beams
}

\author{
Christian Louter*, Jagoda Cupać and Jean-Paul Lebet \\ Steel Structures Laboratory (ICOM), School of Architecture, Civil and Environmental Engineering \\ (ENAC), École Polytechnique Fédérale de Lausanne (EPFL), Lausanne, Switzerland
}

Submitted 20 June 2014

Revised 8 October 2014

Accepted 18 October 2014

\begin{abstract}
The mechanical response of post-tensioned glass beams is explored in this paper. This is done through bending experiments on post-tensioned glass beam specimens with either mechanically anchored or adhesively bonded steel tendons by which a beneficial pre-stress is inflicted on the glass beams. In addition, reference beams with identical geometry but without tendons are tested. From the results of the bending experiments it can be seen that the post-tensioned glass beams reach higher initial fracture loads than the reference glass beams. Furthermore, the post-tensioned glass beams develop a significant post-fracture reserve. From this it is concluded that post-tensioning a glass beam is a feasible concept, which provides increased initial fracture strength and enhanced post-fracture performance.
\end{abstract}

Keywords: Structural glass, post-tensioning, beam, experiment, fracture, strength, redundancy

\section{Introduction}

This paper discusses exploratory experimental investigations into the mechanical response of posttensioned structural glass beams with either mechanically anchored or adhesively bonded steel tendons. It combines and adds to the results published earlier in (Louter, Pérez, Jordan, \& Lebet, 2013) and (Louter, Cupać, \& Debonnaire, 2014).

The main goals of post-tensioning a structural glass beam are 1) to augment the initial fracture strength of the glass beam and 2) to provide a significant post-fracture residual load-carrying capacity.

The first goal of augmenting the fracture strength of the glass beam is envisioned by applying a favourable pre-stress in the glass beam. This pre-stress annuls the bending stress at the lower edge of the glass beam caused by external load and thereby increases the fracture strength of the glass beam. In the current research, the pre-stress is applied either by mechanically anchored or adhesively bonded steel pre-stressing tendons.

The second goal of enhancing the post-fracture performance of structural glass beams is envisioned by the tensile capacity and ductility of the steel tendons. Upon glass fracture, the tendons are expected

\footnotetext{
${ }^{*}$ Corresponding author: Dr. ir. Christian Louter, Steel Structures Laboratory (ICOM), School of Architecture, Civil and Environmental Engineering (ENAC), École Polytechnique Fédérale de Lausanne (EPFL), GC B3 505, Station 18, Lausanne CH-1015, Switzerland. Tel.: +41 21 6932427; Fax: +41 21 6932868; E-mail: christian.louter@epfl.ch.
} 
to bridge the crack(s) in the glass, thereby carrying the tensile forces. Together with a compressive force in the (unfractured) top part of the glass beam, an internal moment capacity is generated, which enables the fractured beam to still carry significant load. This concept resembles the reinforced glass beam concept studied earlier by several authors (Belis, Callewaert, Delincé, \& Van Impe, 2009; Correia, Valarinho, \& Branco, 2011; Cruz \& Pequeno, 2008; Freytag, 2004; Kreher \& Natterer, 2004; Louter, Belis, Veer, \& Lebet, 2012; Ølgaard, Nielsen, \& Olesen, 2009; Palumbo, Palumbo, \& Mazzucchelli, 2005; Speranzini \& Agnetti, 2014; Weller, Meier, \& Weimar, 2010). However, the post-tensioned glass beam concept aims at 'active' steel tendons which contribute to the initial fracture strength of the glass beam, as explained earlier, rather than 'passive' reinforcement sections which are mainly activated upon glass fracture only.

The concept of post-tensioned glass beams has currently been explored in only a limited number of (research) projects (Belis, Louter, Verfaille, Van Impe, \& Callewaert, 2006; Bos, Veer, Hobbelman, \& Louter, 2004; Jordão, Pinho, Martins, Santiago, \& Neves, 2014; Louter et al., 2014; Louter, Nielsen, \& Belis, 2013; Louter, Pérez, et al., 2013; Schober, Gerber, \& Schneider, 2004; Weller \& Engelmann, 2014). Despite their limited number, these projects clearly demonstrate the potential of post-tensioned glass beams. However, investigations are currently still in the preliminary phase and additional studies are needed.

The current paper therefore aims to contribute to the knowledge on post-tensioned glass beams and investigates the mechanical response of such system. This is done through four-point bending tests on $1.5 \mathrm{~m}$ long glass beam specimens. Different series of beam specimens are tested namely 1) beams with mechanically anchored post-tensioning tendons integrated at the recessed top and bottom edge of the glass beams, 2) beams with pre-tensioned tendons adhesively bonded at the lower edge of the glass and 3) reference beams which are identical to the post-tensioned glass beams, but without post-tensioning tendons.

The following sections describe the applied materials and specimens in detail. Furthermore, the post-tensioning method and the four-point-bending procedure are explained. Subsequently, the results of the four-point bending tests are provided, compared and discussed. Finally, conclusions from the study are provided.

\section{Materials \& specimens}

The cross-sections of the beam specimens tested in this study are provided in Fig. 1 . They can be separated in group MECH (mechanically anchored) and group ADH (adhesively bonded). All specimens consisted of three layers of annealed float glass $(6-10-6 \mathrm{~mm})$ with polished edges, which were laminated by means of $1.52 \mathrm{~mm}$ thick SentryGlas ${ }^{\circledR}(\mathrm{SG})$ interlayer sheets. All edge polishing and lamination was executed by professional glass processors, though by different processors per group of specimens. The beams were $1500 \mathrm{~mm}$ long and $125 \mathrm{~mm}$ high.

Group MECH consisted of one series of beam specimens with mechanically anchored posttensioning tendons (MECH-PT) and one series of reference beams without tendons (MECH-REF). For all specimens of group $\mathrm{MECH}$, the inner glass layer was recessed along both edges. The long edges of all glass layers were polished before lamination, whereas the short edges at the beam ends were polished after lamination to guarantee a perfect alignment of the glass where the post-tensioning forces were introduced, see Section 3.1. The applied tendons were stainless steel threaded bars M8, grade 1.4301 , integrated at the recessed beam edges. 

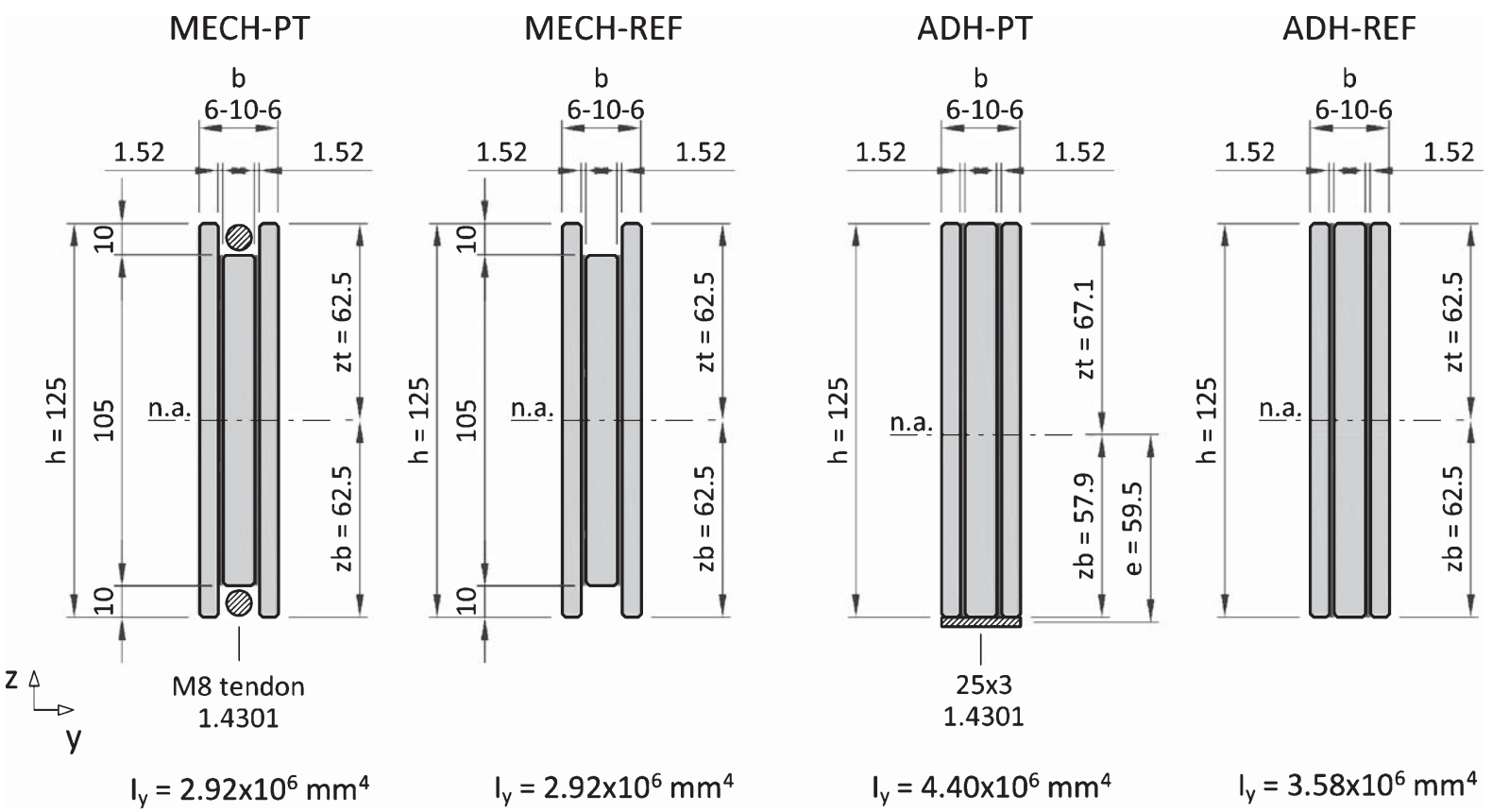

Fig. 1. Cross-section of the different beam specimens tested in this study; $\mathrm{MECH}=$ Mechanically anchored; $A D H=A d h e s i v e l y$ bonded; PT = Post-tensioned; REF = Reference (without tendons); all dimensions are given in $\mathrm{mm}$.

Group ADH consisted of one series of beam specimens with pre-tensioned tendons bonded at the lower edge of the beams (ADH-PT), and one series of reference beams without tendons (ADH-REF). For all specimens of group $A D H$, both the long and the short glass edges were polished after the lamination process. The tendons were stainless steel solid sections, grade 1.4301, with cross-section dimensions of $3 * 25 \mathrm{~mm}$. The tendons were pre-tensioned following the method described in Section 3.2 and were subsequently bonded to the lower edge of the glass by means of a two-component epoxy adhesive, 3M Scotch-Weld DP490 ('3M ${ }^{\top M}$ Scotch-Weld ${ }^{\top M}$ EPX Epoxy Adhesive DP490 Datasheet', 1996), at a targeted adhesive thickness of $0.1 \mathrm{~mm}$.

For each beam series, the estimated second moment of area $I_{y}$ is provided in Fig. 1. This is calculated following the Rules of Steiner, according to Equation 1:

$$
I_{y}=\sum_{i=n}^{n}\left(\frac{b_{i} \cdot h_{i}^{3}}{12} \cdot \frac{E_{i}}{E_{\text {glass }}}+z_{i}^{2} \cdot b_{i} \cdot h_{i} \cdot \frac{E_{i}}{E_{\text {glass }}}\right)
$$

where:

$b_{i}=$ width of the considered component in the section

$h_{i}=$ height of the considered component in the section

$E_{i}=\mathrm{E}$-modulus of the considered component in the section

$E_{\text {glass }}=\mathrm{E}$-modulus of glass

$z_{i}=$ distance of the centroid of the considered component to the overall neutral axis (n.a.) 
The overall neutral axis, here defined as the distance $z_{t}$ from the top edge of the beam, can be determined using Equation 2:

$$
z_{t}=\frac{\sum\left(z_{t, i} \cdot b_{i} \cdot h_{i} \cdot \frac{E_{i}}{E_{\text {glass }}}\right)}{\sum\left(b_{i} \cdot h_{i} \cdot \frac{E_{i}}{E_{\text {glass }}}\right)}
$$

where:

$z_{t, i}=$ distance of the centroid of the considered component to the top edge of the beam

In Equation 1 the second moment area $\left(b_{i} \cdot h_{i}^{3} / 12\right)$ of the individual components within the crosssection and the product of their area $\left(b_{i} \cdot h_{i}\right)$ and the squared distance $z_{i}$ of their central axis to the overall neutral axis are summed. Furthermore, the aspect ratio between the E-modulus $E_{i}$ of the considered component in the cross-section and the E-modulus $E_{\text {glass }}$ of glass, which is the dominant material within the cross-section, is taken into account. For the calculation of $I_{y}$ of the different beam series the following E-moduli have been adopted: $E_{\text {glass }}=70.000 \mathrm{MPa}$ (EN 572-2, 2004), $E_{\text {tendon }}=200.000 \mathrm{MPa}$ (EN 1993-1-4, 2006) and $E_{S G}=493 \mathrm{MPa}$ (Stelzer, 2010).

It should be noted that for the calculation of $I_{y}$ (according to Equation 1 ) the bevels at the polished glass edges are ignored and that nominal dimensions are used. Furthermore, it is assumed that the unbonded M8 threaded bars don't contribute to the inertia $I_{y}$ of the beam series MECH-PT. Reversely, for beam series ADH-PT full composite action is assumed between the glass and the tendon, and as such the tendons are fully incorporated in the calculation of $I_{y}$.

\section{Method}

\subsection{Post-tensioning method for series MECH-PT}

The post-tensioning method applied for beam series MECH-PT is illustrated in Fig. 2. The posttensioning forces were applied at the beam-ends by means of steel end-pieces at which the steel tendons were anchored. To prevent excessive peak stresses, intermediary aluminium sheets were provided between the steel end-pieces and the short ends of the glass beam. Furthermore, as indicated in Section 2, the short ends of the glass beams were polished after the lamination process to guarantee perfect alignment of the glass layers, and thus to prevent excessive peak stresses.

On one end of the beam, see Fig. 2 (left), the tendons were extended by means of hydraulic jacks connected to a manually operated hydraulic pump. On the other end of the beam, see Fig. 2 (right), the force in the tendons was monitored by means of load cells through which the tendons were fed. Once the required post-tensioning force was obtained, the tendons were anchored with screw nuts, and the hydraulic jacks were released and removed. To be able to monitor the forces in the tendons during the bending tests, the load cells remained in position.

For the MECH-PT beams, the applied compressive pre-stress $\left(\sigma_{g l, P}\right)$ can be calculated according to Equation 3:

$$
\sigma_{g l, P}=-\frac{P}{A_{g l}}
$$

where:

$P=$ applied pre-load (total of both tendons, as provided in Table 1 )

$A_{g l}=$ cross-section area of the glass beam ( $=2550 \mathrm{~mm}^{2}$ for the MECH-PT beams) 


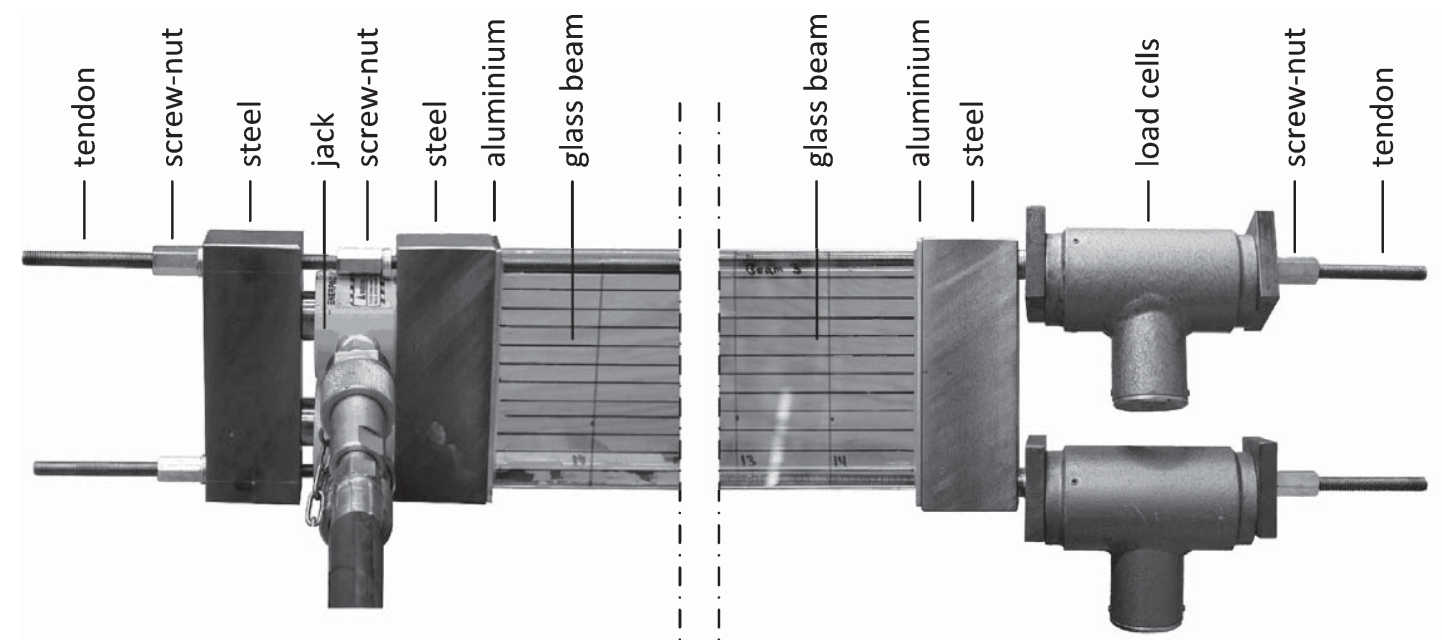

Fig. 2. Post-tensioning method applied for the beam series with the mechanically anchored post-tensioning tendons (MECHPT).

For beam specimen MECH-PT-\#2, the strain in the glass during the post-tensioning procedure was monitored by means of strain gauges. For this, a total of four strain gauges were provided at mid-span of the beam. Three gauges were provided at side A (gauges 1, 2 and 3) and one gauge at the opposite side B (gauge 4), see Fig. 3. Gauges 2 and 4 were located at the neutral axis of the beam, whereas gauges 1 and 3 were positioned $5 \mathrm{~mm}$ from the upper and lower edge of the glass, respectively.

\subsection{Post-tensioning method for series $A D H-P T$}

The post-tensioning method applied for beam series ADH-PT is illustrated in Fig. 4. The tendons were placed in a steel U-section rig, anchored by a bolt at one side (see Fig. 4a) and tensioned at the other side (see Fig. 4b). During tensioning, local strains in the tendons were measured at both ends via strain gauges, see Fig. $4 a$ and $b$, from which the force in the tendons was derived. Subsequently, the two-component epoxy adhesive was applied on the tendons, and the glass beams were positioned on top, see Fig. 5. The adhesive was left to cure for at least three days before releasing the tendons. The beams were tested in four-point bending seven to ten days after pre-stressing.

For the ADH-PT beams, the applied pre-stress at the top $\left(\sigma_{g l, t, P}\right)$ and bottom edge $\left(\sigma_{g l, b, P}\right)$ of the glass can be calculated following Equations 4 and 5, respectively:

$$
\begin{gathered}
\sigma_{g l, t, P}=-\frac{P}{A_{e q}}+\frac{P \cdot e}{I_{y}} \cdot z_{t} \\
\sigma_{g l, b, P}=-\frac{P}{A_{e q}}-\frac{P \cdot e}{I_{y}} \cdot z_{b}
\end{gathered}
$$

where:

$P=$ applied pre-load (as provided in Table 1)

$A_{e q}=A_{g l}+n \cdot A_{t}$ equivalent cross-section area of the beam

$A_{g l}=$ cross-section area of the glass beam ( $=2750 \mathrm{~mm}^{2}$ for the ADH-PT beams) 


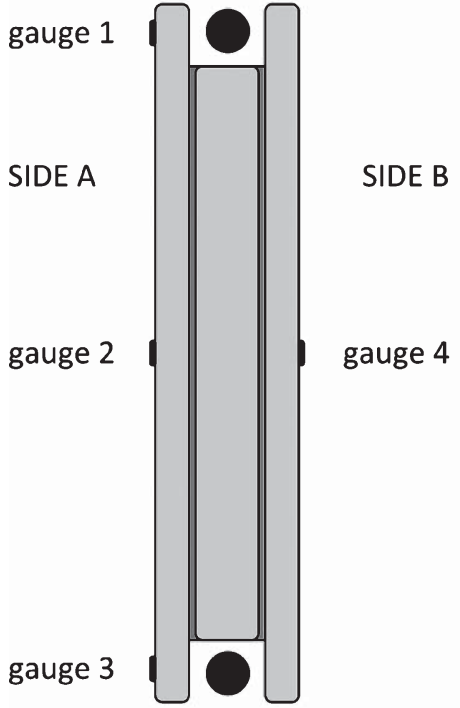

(a)

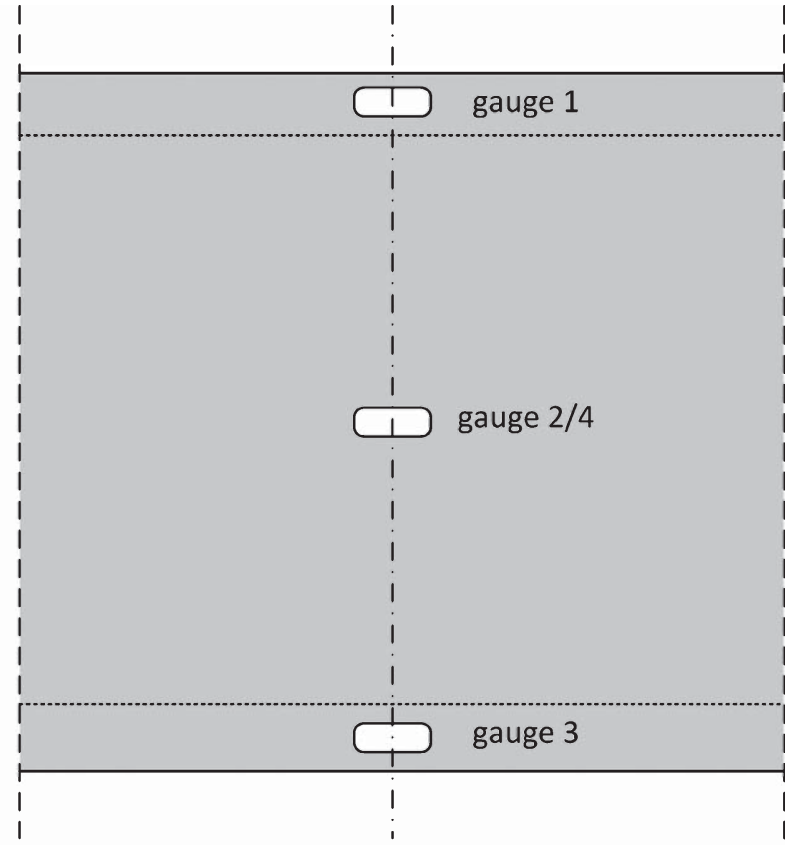

(b)

Fig. 3. Strain gauges applied at specimen MECH-PT-\#2; (a) cross-section view; (b) side view of the beam at mid-span.



(a)

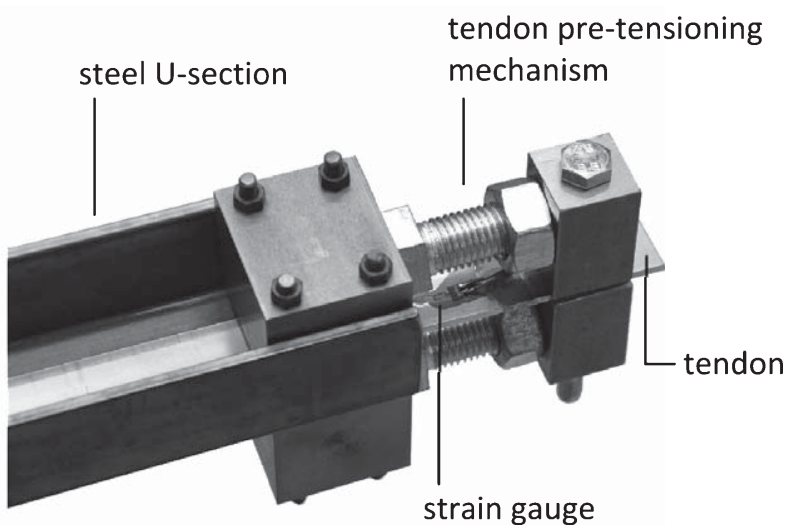

(b)

Fig. 4. Post-tensioning method applied for the beam series with the pre-tensioned adhesively bonded tendons (ADH-PT). (a) Tendon anchorage by means of bolt in temporary tensioning rig; (b) Tendon tensioning mechanism.

$$
\begin{aligned}
& A_{t}=\text { cross-section area of the steel tendon ( }=75 \mathrm{~mm}^{2} \text { for the ADH-PT beams) } \\
& n=E_{\text {tendon }} / E_{\text {glass }} \\
& e=\text { eccentricity of the applied tendon pre-load } P \text { to the neutral axis (see Fig. 6) }
\end{aligned}
$$



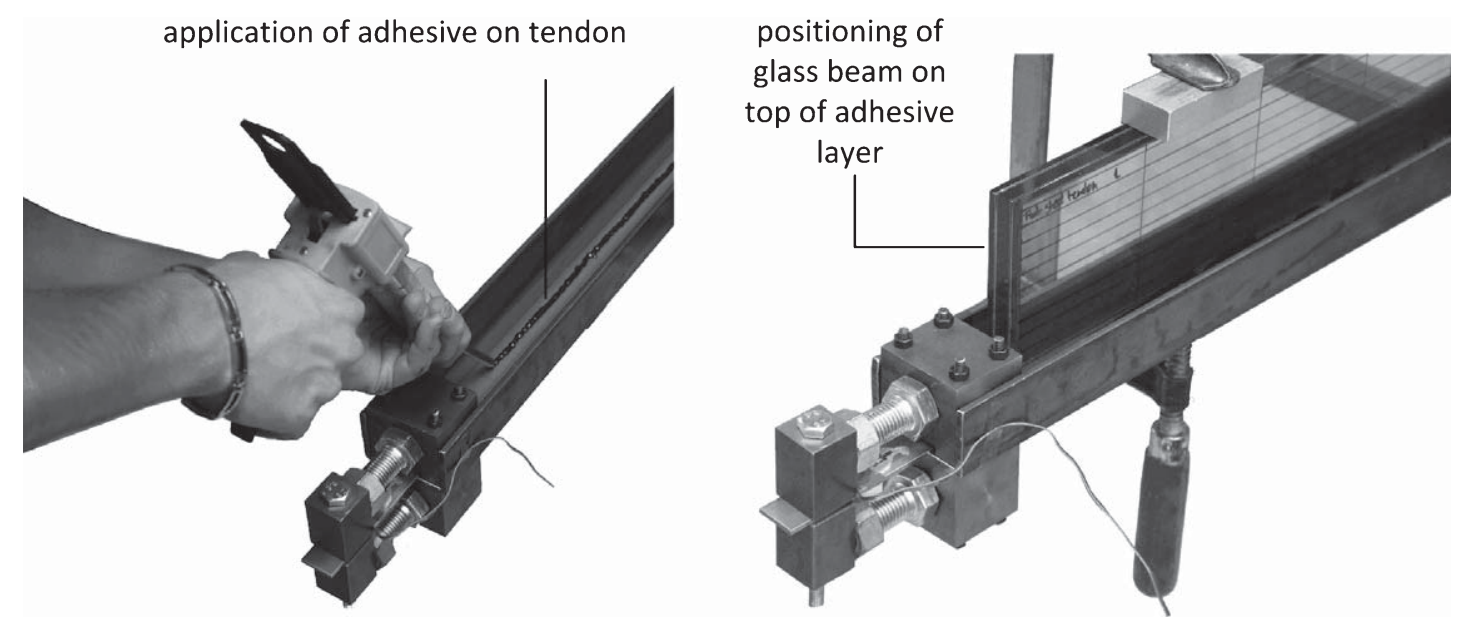

Fig. 5. Applied method for bonding the pre-tensioned tendons to the lower edge of the glass beam (series ADH-PT).

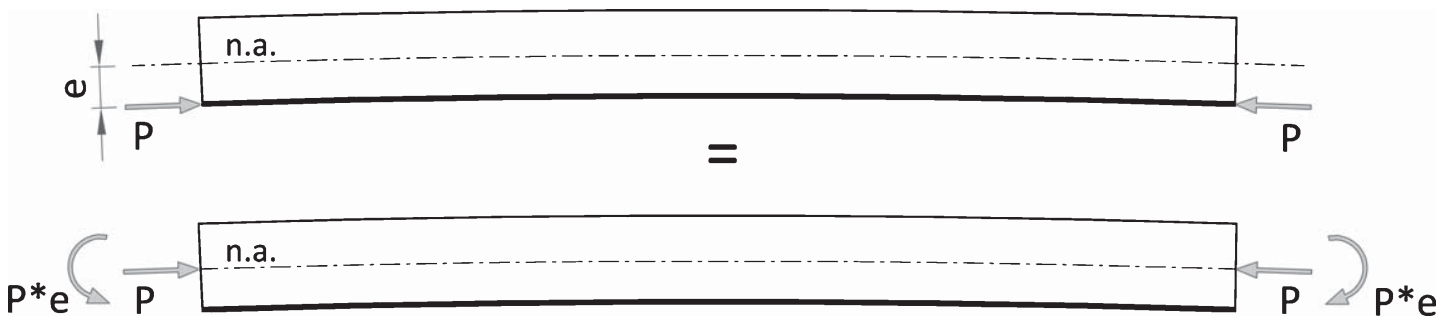

Fig. 6. Post-tensioning force balance on ADH-PT beam series.

$z_{t}=$ distance from the neutral axis to the top glass edge (see Fig. 1 )

$z_{b}=$ distance from the neutral axis to the bottom glass edge (see Fig. 1)

The first parts of Equations 4 and 5 account for a compressive pre-stress which can be envisioned by shifting the applied pre-load $P$ to the neutral axis over distance $e$, see Fig. 6 . The second parts of the equations account for the bending stress resulting from an upwards-bending moment $P \cdot e$ inflicted by the tendon.

\subsection{Four-point bending procedure}

After post-tensioning, the beams were tested in four-point bending, see Fig. 7. For this, a custommade support frame was mounted on a universal tension-compression machine (Zwick $500 \mathrm{kN}$ ). The support span amounted to $1.4 \mathrm{~m}$ with a load span of $0.4 \mathrm{~m}$. Lateral supports were provided at a centre span of $0.55 \mathrm{~m}$. A fixed displacement rate of $1 \mathrm{~mm} / \mathrm{min}$ was applied until glass fracture, after which the displacement rate was augmented to $2 \mathrm{~mm} / \mathrm{min}$ and $5 \mathrm{~mm} / \mathrm{min}$, respectively, to reduce test duration. Overall, the duration of a single test amounted to about 30-45 minutes. During the test, the applied force $(F)$ and machine displacement were measured and recorded. 

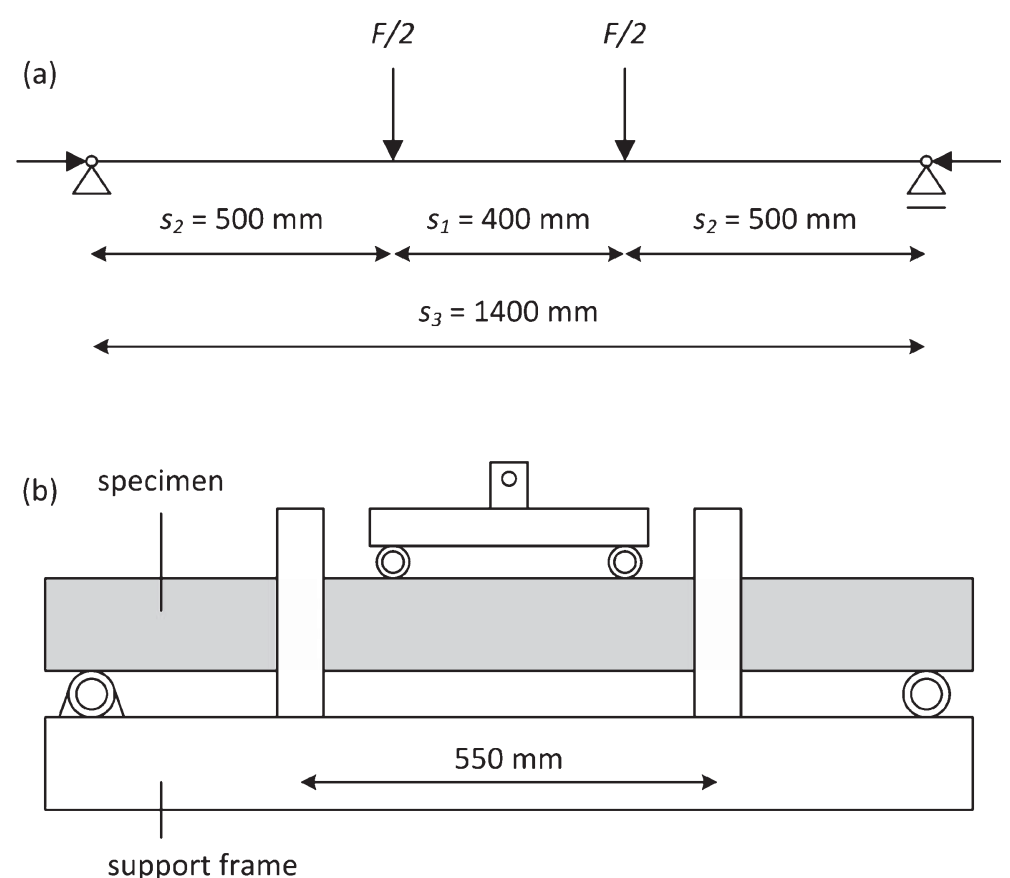

Fig. 7. Schematic representation of the applied four-point-bending configuration.

The applied bending stress either at the top $\left(\sigma_{g l, t, F}\right)$ or bottom $\left(\sigma_{g l, b, F}\right)$ glass edge is calculated by Equations 6 and 7, respectively:

$$
\begin{gathered}
\sigma_{g l, t, F}=\frac{\frac{F}{2} \cdot s_{2} \cdot z_{t}}{I_{y}} \\
\sigma_{g l, b, F}=\frac{\frac{F}{2} \cdot s_{2} \cdot z_{b}}{I_{y}}
\end{gathered}
$$

where:

$F=$ applied force

$s_{2}=$ distance between support and load point (see Fig. 7)

\section{Results}

The results of the four-point-bending tests are provided in Table 1 and Figs. 8-17.

Table 1 presents the pre-load as applied by the post-tensioning tendons, the fracture load and the maximum post-fracture load recorded during the four-point bending test and the post-fracture reserve. The latter expresses the maximum post-fracture load as a percentage of the initial fracture load.

Figures 8-11 provide the force-displacement curves resulting from the four-point-bending tests. All beam series show initial linear elastic response until fracture of the glass occurs. After initial glass fracture, the reference beams show a significant drop in load and a limited post-fracture reserve, see Figs. 9 and 11. The post-tensioned beam series, however, demonstrate significant post-fracture reserves and maximum post-fracture load values higher than the initial fracture loads, see Figs. 8 
Table 1

Results of the four-point-bending tests

\begin{tabular}{lcccc}
\hline Spec. No. & Pre-load & $\begin{array}{c}\text { Fracture load } \\
F_{\text {fracture }}\end{array}$ & $\begin{array}{c}\text { Maximum post-fracture load } \\
{[\mathrm{kN}]}\end{array}$ & $\begin{array}{c}\text { Post-fracture reserve } \\
F_{\text {post-fracture }} \\
{[\mathrm{kN}]}\end{array}$ \\
\hline MECH-PT-\#1 & $P$ & 12.0 & 16.6 & 139 \\
MECH-PT-\#2 & $49.6^{*}$ & 11.9 & 15.4 & 129 \\
MECH-PT-\#3 & $50.6^{*}$ & 11.6 & 16.8 & 144 \\
Mean & $49.9^{*}$ & 11.8 & 16.3 & 138 \\
MECH-REF-\#1 & 50.0 & 8.3 & 2.4 & 28 \\
MECH-REF-\#2 & - & 7.3 & 2.5 & 35 \\
MECH-REF-\#3 & - & 8.4 & 2.6 & 30 \\
Mean & - & 8.0 & 2.5 & 31 \\
ADH-PT-\#1 & - & 18.1 & 35.0 & 193 \\
ADH-PT-\#2 & $23.9^{* *}$ & 20.0 & 35.1 & 175 \\
ADH-PT-\#3 & $28.3^{* *}$ & 22.3 & 36.6 & 164 \\
Mean & $28.2^{* *}$ & 20.1 & 35.6 & 178 \\
ADH-REF-\#1 & 26.8 & 7.8 & 2.6 & 33 \\
AHD-REF-\#2 & - & 9.7 & 2.8 & 28 \\
Mean & - & 8.8 & 2.7 & 31
\end{tabular}

*Total of the two tendons. The applied force was equal in both tendons. ${ }^{* *}$ Corrected values from (Louter et al., 2014).

and 10. Figure 12 provides a comparison of typical force-displacement curves of the different beam series.

Figures 13-15 show typical crack patterns observed for the different beam series. The cracks in the glass originate from the lower (tensile) edge of the glass beams and propagate upwards. The reference beams typically show a localized V-shaped cracking pattern, see Figure 13.

The post-tensioned beams of both series MECH-PT and ADH-PT show distributed cracking and a distinct zone where ultimate compressive failure of the glass occurred, see Figs. 14 and 15. The post-tensioned beams of series ADH-PT typically exhibit debonding of the tendons, see Fig. 15.

Figure 16 shows the results of the strain gauge measurements performed during the post-tensioning procedure of specimen MECH-PT-\#2.

Figure 17 shows the force in the tendons of specimen MECH-PT-\#3 during the four-point bending procedure.

\section{Discussion}

\subsection{Series MECH; glass beams with mechanically anchored tendons}

From the results of series MECH-PT and MECH-REF, the following is observed.

Firstly, it can be seen that the post-tensioned MECH-PT beams reach higher initial fracture loads than the MECH-REF reference beams. Whereas the reference beams reach an average initial fracture load of $8.0 \mathrm{kN}$, this amounts to $11.8 \mathrm{kN}$ for the mechanically post-tensioned beams, see Table 1 . 
Series MECH-PT



Fig. 8. Force-displacement curves of series MECH-PT, post-tensioned beams with unbonded M8 tendons.

Series ADH-PT

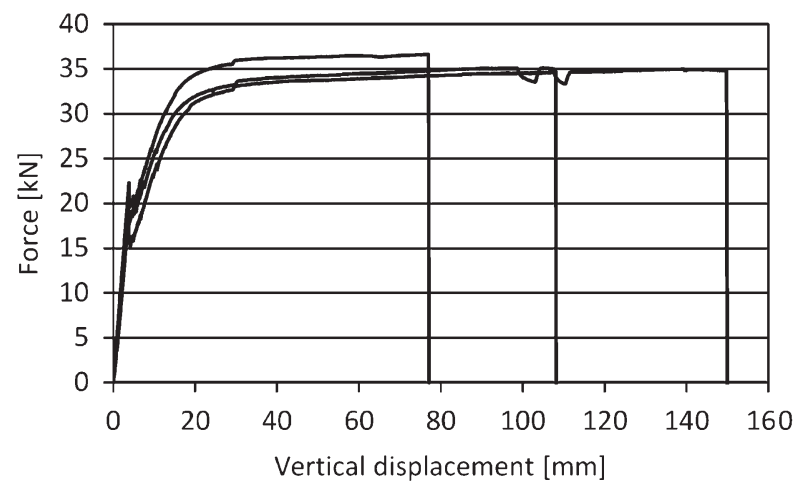

Fig. 10. Force-displacement curves of series ADH-PT, post-tensioned beams with adhesively bonded tendons.
Series MECH-REF

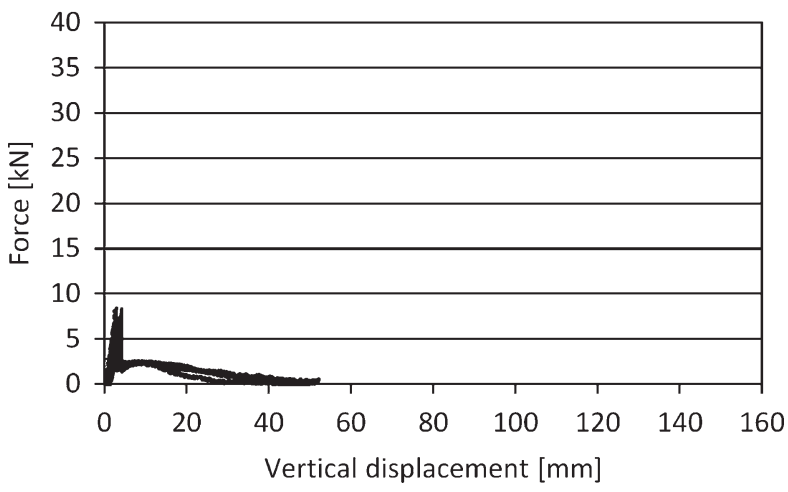

Fig. 9. Force-displacement curves of series MECH-REF, reference beams without tendons.

Series ADH-REF

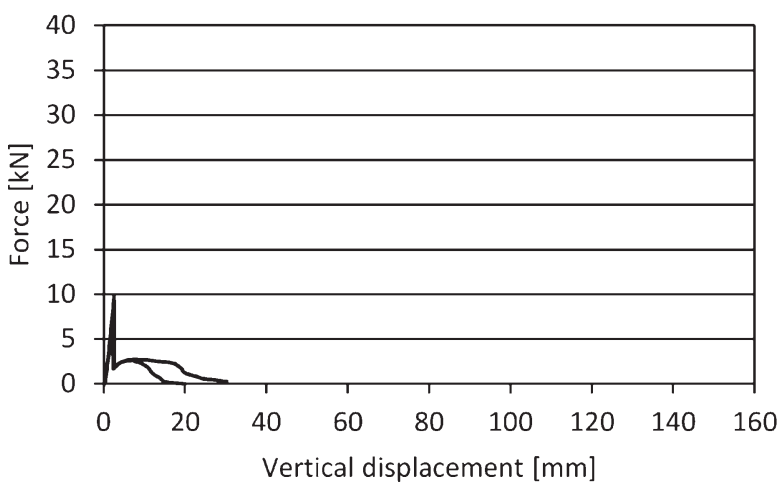

Fig. 11. Force-displacement curves of series ADH-REF, reference beams without tendons.

$$
\text { - - ADH-PT - - . MECH-PT }
$$$$
\text { - MECH/ADH -REF }
$$

Series MECH \& ADH

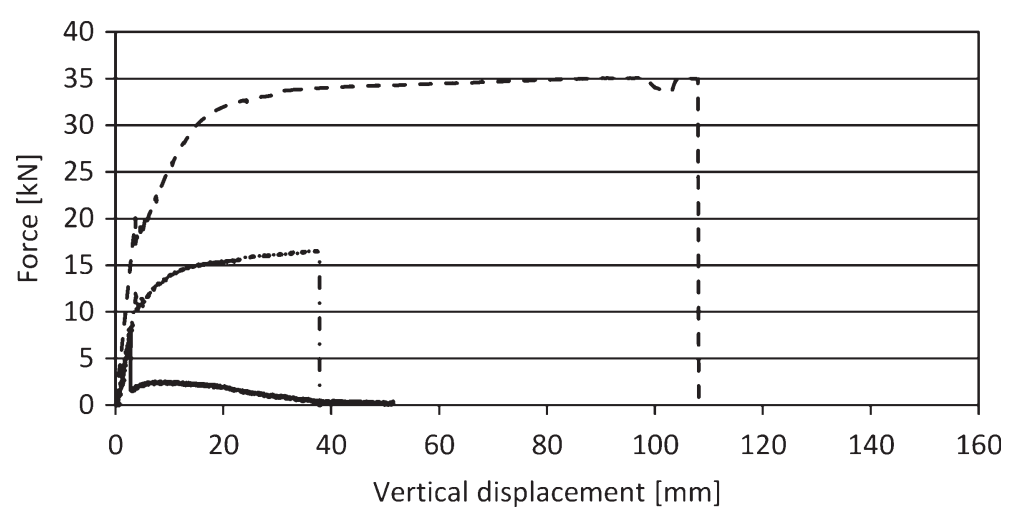

Fig. 12. Comparison of typical force-displacement curves of all beam series. 


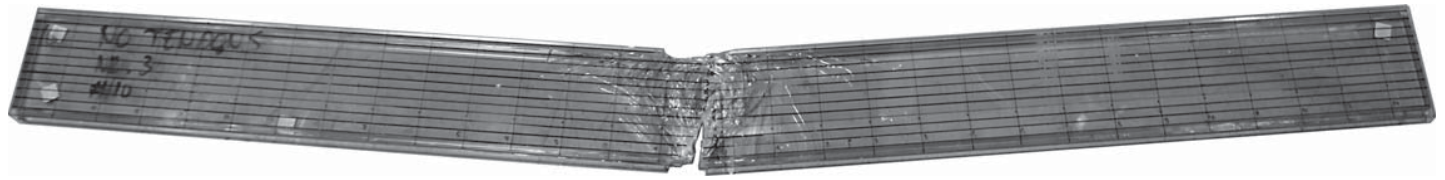

Fig. 13. Typical localized cracking in reference beams.

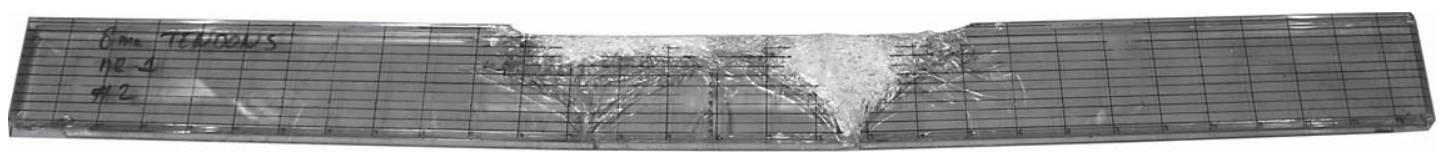

Fig. 14. Typical distributed cracking in MECH-PT specimens (tendons not shown on picture).

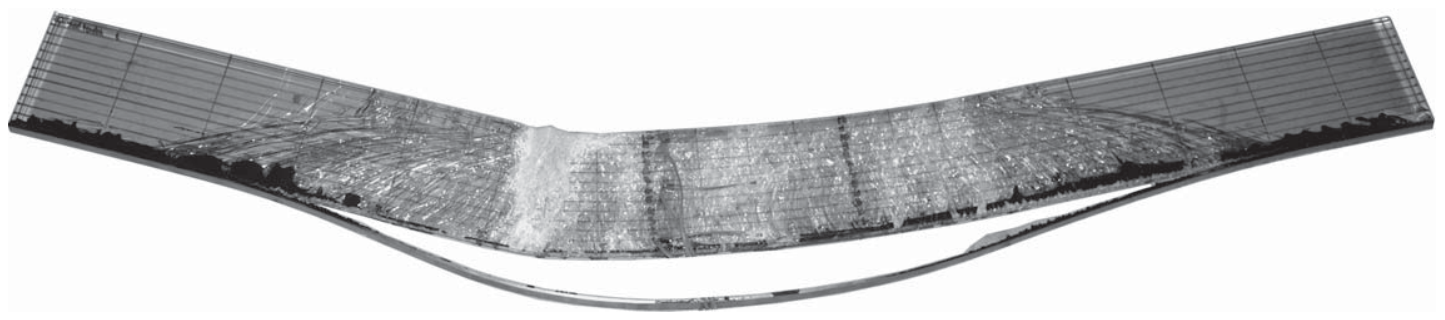

Fig. 15. Typical distributed cracking in ADH-PT specimens and significant yielding of tendon.

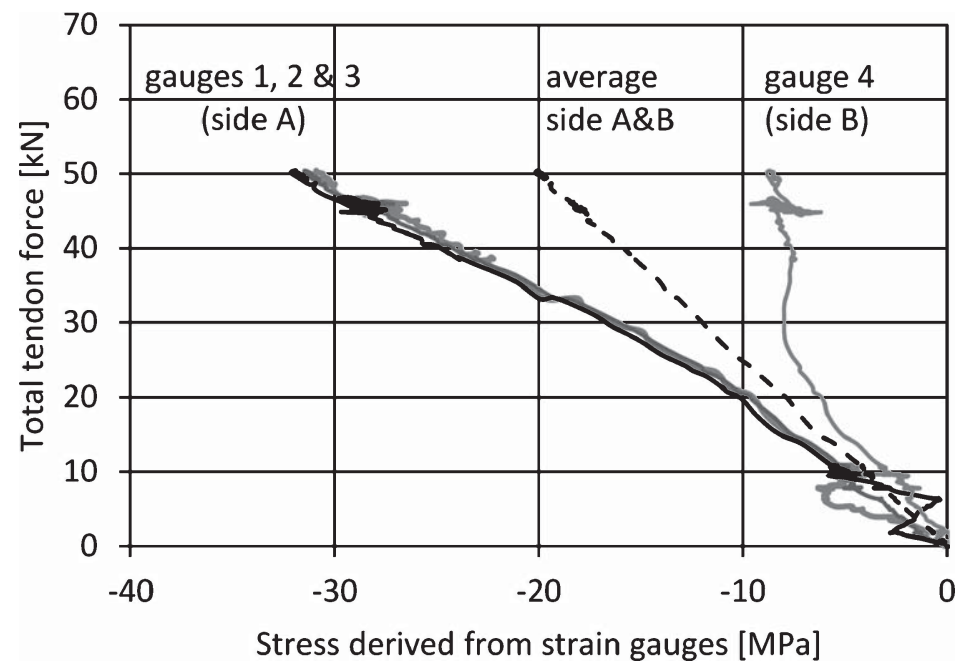

Fig. 16. Stress plots derived from strain gauge measurement during post-tensioning of specimen MECH-PT-\#2.

This increase in initial fracture strength of the mechanically post-tensioned beams is explained by the compressive pre-stress applied by the post-tensioning tendons.

Figure 18 provides an overview of the stress distribution along the height of the mechanically post-tensioned MECH-PT glass beams at the verge of initial glass fracture, based on mean values 


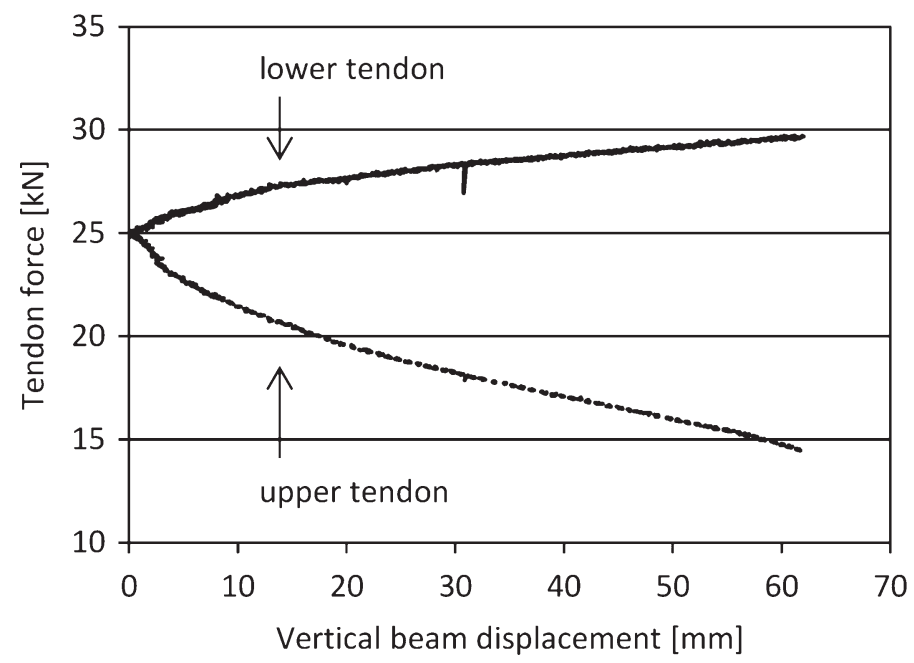

Fig. 17. Force measurements in the tendons of specimen MECH-PT-\#3 made during the four-point bending test.

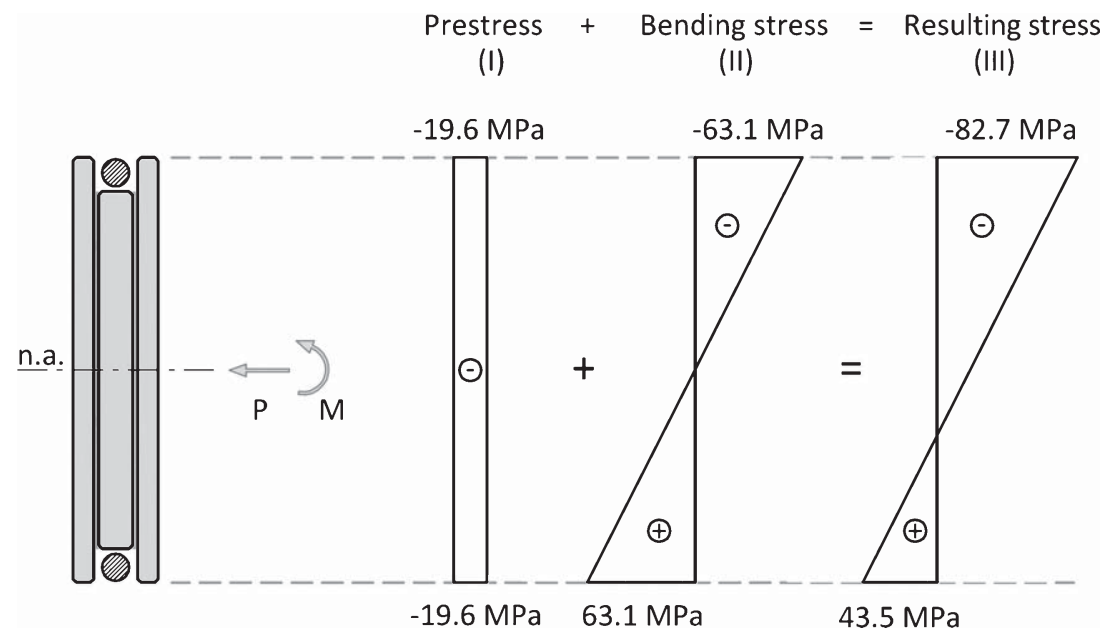

Fig. 18. Stress distribution in the glass of MECH-PT beams at the verge of initial glass fracture, based on mean values.

provided in Table 1. The Figure consists of three parts, namely (I) the applied compressive pre-stress as calculated from Equation 3, (II) the applied bending stress at the point of initial glass fracture as calculated from Equations 6 and 7, and (III) the resulting stress distribution in the glass which is a sum of (I) and (II). It can be seen that the resulting tensile (fracture) stress (III) at the lower edge of the glass amounts to $43.5 \mathrm{MPa}$. This value is similar to the tensile fracture stress of the MECH-REF reference beams, which amounts to $42.8 \mathrm{MPa}$, as can be calculated by Equation 7. Taking into account the known and rather significant scatter in glass strength, it can be concluded that post-tensioning the glass beams has been successful and that the observed increase in beam strength is indeed likely to originate fully from the applied compressive pre-stress.

For specimen MECH-PT-\#2 an attempt was made to record the pre-stress applied during the posttensioning procedure by means of strain gauges bonded at either side of the beam, as explained in 
Section 3.1 and Fig. 3. From the strain gauge measurements provided in Fig. 16, it can be seen that the pre-compressive stress at side $A$ reaches higher values than at side $B$. At a total pre-tensioning load of $50 \mathrm{kN}$, a pre-compressive stress of $-31.5 \mathrm{MPa}$ is observed at side $A$, whereas this amounts to about $-8.5 \mathrm{MPa}$ at side $\mathrm{B}$. This indicates that the specimen is - to a limited extent - bending along its weak axis during the post-tensioning procedure. This bending may originate from a misalignment of the tendons in the recessed notches, i.e. the tendons are not perfectly centred, and in fact it was observed during some attempts of the post-tensioning procedure that re-positioning of the tendons in the recessed edges could reduce the stress differences between side A and B. In addition, it is assumed that initial imperfections, i.e. global bow of the beams (Belis, Mocibob, Luible, \& Vandebroek, 2011), may have enlarged this effect. Since only one specimen was instrumented with strain gauges, it could not be observed to what extent this effect also occurred in the other specimens. Further studies will focus in more detail on this effect, thereby also determining the lateral deflection of the beam specimens during the post-tensioning procedure. However, it should be noted that all gauges on side $A$ indicated the same stress level, thus uniform loading over the full height of the beam was obtained. Averaging the pre-compressive stress at side $A$ and $B$ results in a mean pre-compressive stress of $(-31.5-8.5) / 2=-20 \mathrm{MPa}$, which is indeed very close to the calculated pre-stress of -19.6 $\mathrm{MPa}$, as provided in Fig. 18.

Secondly, it can be seen that the post-tensioned MECH-PT specimens develop a significant postfracture resistance. Whereas the reference beams demonstrate a single crack in the glass and a post-fracture reserve of only about $30 \%$ of their initial fracture strength, the mechanically posttensioned beams show repetitive and distributed cracking of the glass and reach about $140 \%$ of their initial fracture strength, see Table 1.

For the reference beams, the post-fracture load-carrying mechanism is originating from the SG interlayer sheets (Belis, Depauw, Callewaert, Delincé, \& Van Impe, 2009). In the reference beams, fracture of the glass occurs in all three glass layers at the same location. At that location the SG interlayer sheets are the only 'intact' components able to transfer tensile forces over the crack in the glass. Together with a compressive force in the top part of the beam, a post-fracture load-carrying mechanism is generated. However, the stiffness of the interlayer is relatively low, which results in limited post-fracture strength of the beams. Furthermore, under continued loading, the interlayer starts to deform plastically, which causes a plastic hinge in the beam and a gradual reduction of the post-fracture load, as can be seen from Figs. 9 and 11.

For the mechanically post-tensioned beams (MECH-PT) the post-fracture load-carrying capacity is generated by the lower tendon that bridges the $\operatorname{crack}(\mathrm{s})$ in the glass. A tensile force in the tendon and a compressive force in the top part of the glass beam generate an internal moment capacity that allows the fractured beam to still carry load. Under continued loading the fractured beam is even able to carry load beyond its initial fracture load, which causes additional cracks in the glass to occur.

This increasing post-fracture load-carrying capacity of the post-tensioned beams is associated with a gradually increasing tensile force in the lower tendon and a gradually decreasing force in the upper tendon, as can be seen from Fig. 17. Due to yielding of the lower tendon, the beams show a ductile post-fracture response. In addition, progressive cracking of the glass further contributes to a decrease in post-fracture stiffness of the beams. Collapse is finally caused by complete failure of the compression zone in the glass, see Fig. 14. Whether this is caused by overstressing of the glass or by local instability of the compression zone could not be observed during the bending experiments and needs further study. 


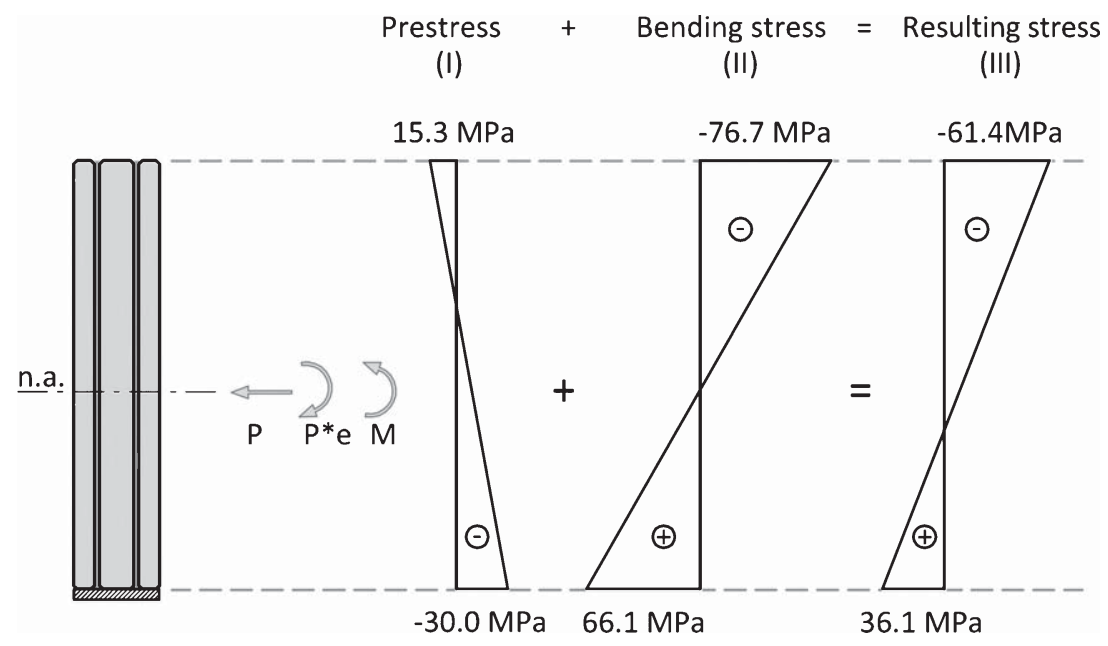

Fig. 19. Stress distribution in the glass of ADH-PT beams at the verge of initial glass fracture, based on mean values.

\subsection{Series ADH; glass beams with adhesively bonded tendons}

From the results of series ADH-PT and ADH-REF, the following is observed.

Firstly, it can be seen that the post-tensioned beam specimens ADH-PT reach higher initial fracture loads than the reference beams ADH-REF. The reference beams fracture at an average load of $8.8 \mathrm{kN}$, while this amounts to $20.1 \mathrm{kN}$ for the post-tensioned ADH-PT beams, see Table 1 . This difference in initial fracture strength is again explained by the beneficial pre-stress inflicted by the post-tensioning tendons.

Figure 19 shows the stress distribution in the post-tensioned ADH-PT beams at the verge of initial glass fracture, thereby making use of Equations 4-7 and applying mean values as provided in Table 1. The tensile fracture stress (III) at the lower glass edge amounts to $36.1 \mathrm{MPa}$. This value is similar to the fracture stress of the ADH-REF reference glass beams, which amounts to $38.4 \mathrm{MPa}$ as can be calculated from Equation 7. This again indicates that the glass strength is similar for the ADH-PT and ADH-REF beams, which means that the post-tensioning method is successful and that the increase in beam strength of the ADH-PT beams is likely to originate fully from the beneficial pre-stress inflicted by the tendons.

Secondly, it can be seen that the post-tensioned beams develop a significant post-fracture resistance, whereas this is largely absent for the reference glass beams. The post-fracture load-carrying capacity amounts to about $180 \%$ of the initial fracture load for the series ADH-PT and about $30 \%$ for the reference beams, see Table 1.

For the series ADH-PT post-tensioned beams the post-fracture load-carrying capacity is, similarly to the series MECH-PT post-tensioned beams, generated by a tensile force in the tendon and a compressive force in the upper zone in the glass. The transfer of forces between the tendon and the glass fully relies on shear in the epoxy adhesive bond. This adhesive bond is sufficiently strong to transfer the shear load between the tendon and the glass and even enables the tendon to reach the yielding point. However, under continued loading gradual adhesive failure and debonding of the tendon - from mid-span outwards - is observed. Final beam collapse is associated with full debonding of the tendon - from mid-span to one of the beam ends - and explosive failure of the 
glass compression zone, see Fig. 15. Which phenomenon occurs first could not be observed during the experiments and will need to be investigated in future research.

Finally, it is observed that the ADH-PT beams reach higher post-fracture strength levels than the MECH-PT beams, see Fig. 12. This is explained by the larger cross-section area of the tendons that are applied in the ADH-PT beams than in the MECH-PT beams. This allows the tendons in the ADH-PT beams to carry higher forces than the tendons in the MECH-PT beams. A higher tensile capacity of the tendons implies that the beams can reach higher post-fracture loads due to an enhanced internal moment capacity.

\section{Conclusions}

In this study, bending experiments have been conducted on post-tensioned glass beams and reference glass beams. From the results of the bending experiments it is concluded that post-tensioning structural glass beams, by means of mechanically anchored or adhesively bonded tendons, is a feasible concept which provides increased initial fracture strength and enhanced post-fracture performance.

The post-tensioned glass beams reach initial fracture loads which amount to $150-230 \%$ of the initial fracture load of the reference glass beams. This is due to the pre-stress applied by the tendons, which annuls the tensile bending stress at the lower glass edge and thus augments the fracture strength of the beam. Furthermore, the post-tensioned glass beams develop a significant post-fracture reserve and reach post-fracture load levels which amount to $140-180 \%$ of their initial fracture load. This post-fracture reserve is generated by the tendons that successfully bridge the cracks in the glass and provide a post-fracture load-carrying mechanism.

It should be noted, however, that the results presented here are merely exploratory. More in depth studies into post-tensioning glass beams are required. Especially the concept of post-tensioning glass beams with adhesively bonded pre-tensioned tendons requires specific attention. Thermal expansion differences between the tendon and the glass may cause significant stress in the adhesive layer and thus need to be addressed. Furthermore, permanent stressing of the adhesive due to the pre-stressing tendon may cause creep in the adhesive layer and thus reduction of pre-stress over time. For this, it might well be that a solution can be found in combining the concept of adhesively bonded tendons with an additional mechanical anchor. These and various other aspects will be investigated by the authors in near-future studies.

\section{Acknowledgments}

The Swiss National Science Foundation is gratefully acknowledged for funding the present research through SNF Grant 200021_143267. Additionally, the contribution of MSc students Arno Pérez, Thibaut Jordan and Mathieu Debonnaire in performing part of the tests for this research is gratefully acknowledged. Finally, the COST Action TU0905 Structural Glass - Novel design methods and next generation products is gratefully acknowledged for providing a research network on structural glass.

\section{References}

3M ${ }^{\mathrm{TM}}$ Scotch-Weld ${ }^{\mathrm{TM}}$ EPX Epoxy Adhesive DP490 Datasheet (1996). Retrieved October 02, 2014, from http://catalogue.3m.eu/ en_EU/EU-mro/3M_Adhesives/Structural_Adhesive_2_Part_Duo-Pack_-_Epoxy/Scotch-Weld\%E2\%84\%A2_EPX Epoxy_Adhesive DP490/Ep oxy_Adhesive 
Belis, J., Callewaert, D., Delincé, D., \& Van Impe, R. (2009). Experimental failure investigation of a hybrid glass/steel beam. Engineering Failure Analysis, 16(4), 1163-1173. doi:10.1016/j.engfailanal.2008.07.011

Belis, J., Depauw, J., Callewaert, D., Delincé, D., \& Van Impe, R. (2009). Failure mechanisms and residual capacity of annealed glass/SGP laminated beams at room temperature. Engineering Failure Analysis, 16(6), 1866-1875. doi:10.1016/j.engfailanal.2008.09.023

Belis, J., Louter, C., Verfaille, K., Van Impe, R., \& Callewaert, D. (2006). The effect of post-tensioning on the buckling behaviour of a glass T-beam. In International Symposium on the Application of Architectural Glass ISAAG (pp. 129-136).

Belis, J., Mocibob, D., Luible, A., \& Vandebroek, M. (2011). On the size and shape of initial out-of-plane curvatures in structural glass components. Construction and Building Materials, 25(5), 2700-2712. doi:10.1016/j.conbuildmat.2010.12.021

Bos, F., Veer, F., Hobbelman, G., \& Louter, C. (2004). Stainless steel reinforced and post-tensioned glass beams. In ICEM12- 12th International Conference on Experimental Mechanics.

Correia, J. R., Valarinho, L., \& Branco, F. A. (2011). Post-cracking strength and ductility of glass-GFRP composite beams. Composite Structures, 93(9), 2299-2309. doi:10.1016/j.compstruct.2011.03.018

Cruz, P. J. S., \& Pequeno, J. (2008). Timber-glass composite beams: Mechanical behaviour \& architectural solutions. In Challenging Glass (pp. 439-448).

EN 1993-1-4. Eurocode 3-Design of steel structures - Part 1-4: General rules - Supplementary rules for stainless steels (2006).

EN 572-2 (2004). Glass in building - Basic soda lime silicate glass products - Part 2: Float glass.

Freytag, B. (2004). Glass-concrete composite technology. Structural Engineering International, 14(2), 111-117. doi:10.2749/101686604777 963991

Jordão, S., Pinho, M., Martins, J. P., Santiago, A., \& Neves, L. C. (2014). Behaviour of laminated glass beams reinforced with pre-stressed cables. Steel Construction, 7(3), 204-207. doi:10.1002/stco.201410027

Kreher, K., \& Natterer, J. (2004). Timber-glass-composite girders for a hotel in Switzerland. Structural Engineering International, 2, $149-151$.

Louter, C., Belis, J., Veer, F., \& Lebet, J.-P. (2012). Structural response of SG-laminated reinforced glass beams; experimental investigations on the effects of glass type, reinforcement percentage and beam size. Engineering Structures, 36, 292-301. doi:10.1016/j.engstruct.2011.12. 016

Louter, C., Cupać, J., \& Debonnaire, M. (2014). Structural glass beams pre-stressed by externally bonded tendons. In GlassCon Global (pp. 460-469).

Louter, C., Nielsen, J. H., \& Belis, J. (2013). Exploratory experimental investigations on post-tensioned structural glass beams. In The $2 n d$ International Conference on Structures and Architecture ICSA 2013 (pp. 358-365).

Louter, C., Pérez, A., Jordan, T., \& Lebet, J.-P. (2013). Post-tensioned structural glass beams - Experimental investigations. In COST Action TU0905 Mid-term Conference on Structural Glass (pp. 277-284).

$\varnothing$ lgaard, A. B., Nielsen, J. H., \& Olesen, J. F. (2009). Design of mechanically reinforced glass beams: Modelling and experiments. Structural Engineering International, 19(2), 130-136. doi:10.2749/101686609788220169

Palumbo, D., Palumbo, M., \& Mazzucchelli, M. (2005). A new roof for the XIIIth century "Loggia de Vicari” (Arquá Petrarca - PD - Italy) based on structural glass trusses: A case study. In Glass Processing Days (pp. 434-435).

Schober, H., Gerber, H., \& Schneider, J. (2004). Ein Glashaus für die Therme in Badenweiler. Stahlbau, 73, 886-892.

Speranzini, E., \& Agnetti, S. (2014). Strengthening of glass beams with steel reinforced polymer (SRP). Composites Part B: Engineering, 67, 280-289. doi: 10.1016/j.compositesb.2014.06.035

Stelzer, I. (2010). High performance laminated glass. In Challenging Glass 2 (pp. 467-474).

Weller, B., \& Engelmann, M. (2014). Deformation of Spannglass beams during post-tensioning. In Challenging Glass 4 \& COST Action TU0905 Final Conference (pp. 285-294).

Weller, B., Meier, A., \& Weimar, T. (2010). Glass-steel beams as structural members of façades. In Challenging Glass 2 (pp. 517-524). 